\title{
ANALYSIS OF MOVEMENT OF TINY SPHERICAL CONDUCTOR IN SYNTHETIC ESTER IN POWER TRANSFORMER USING CFD
}

\author{
N. Vasantha Gowri \\ Department of Electrical and Electronics Engineering, \\ Chaitanya Bhararthi Institute of Technology, \\ Hyderabad Telangana, India
}

\begin{abstract}
Power transformer is very important part of a power sector. Power transformers are of various rating, those are used in power sector based on requirement. Power Transformers are mostly oil filled Transformers. The fluid which is filled inside the power transformer acts as a coolant as well as insulating agent of the transformer. This fluid may consists of number of diminutive conducting and non-conducting particles as a result of age and continuous usage. Non-conducting particles are considered to be non harmful virus the conducting particles which are called micro conductors are considered to be as hazardous to transformer. One of the important consequences of presence of these particles is partial discharge (PD). Stress formed by these conducting particles lead to partial discharges inside the transformer. This paper is intended to study the behaviour of such particles which are of spherical shape inside the transformer when synthetic ester is used as cooling agent and insulating medium using computational fluid dynamics (CFD).
\end{abstract}

Key words: Power tranasformer, systhetic ester, computational fluid dynamics partial discharge.

Cite this Article: N. Vasantha Gowri, Analysis of Movement of Tiny Spherical Conductor in Synthetic Ester in Power Transformer Using CFD, International Journal of Electrical Engineering and Technology, 11(4), 2020, pp. 1-7.

https://iaeme.com/Home/issue/IJEET?Volume=11\&Issue $=4$

\section{INTRODUCTION}

Power Transformers are used in power stations and substations to provide suitable voltages to transmit and distribute. Based on the place of utilisation the power transformer ratings are different. Generally, power transformers are considered to have very high rating when compared to distribution Transformers. Due to this high rating, the risks related to Power Transformers are also high. One of the perils related to failure of the transformer due to different reasons is considered to be partial discharge (PD). Partial discharge may happen inside the transformer due to many reasons. A fixed flowing fluid is used to cool the

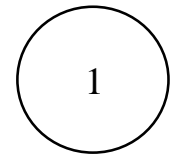


transformer winding and acts as an insulating medium. This fluid is generally called as transformer oil. Hydrocarbon oil is normally used in transformer. Availability of conducting materials inside the transformer in the winding space is also listed as one of the main reasons causing partial discharge. These small particles freely move along with insulating oil. When conducting material is coming in contact with energized winding then the stress is formed on the particle. If this stress exceeds the value of threshold of insulating medium then results in partial discharge. Different insulating fluids has different threshold for breakdown voltage. Numbers of research works have been carried out to find alternative for hydrocarbon oil and suggested few fluids to be suitable in place of hydrocarbon oil. In the recent times synthetic ester is being suggested to be used as insulating fluid by many of the researchers. A work by Perrier et al. [1] illustrated that best mixture of liquid insulation enables optimization of the power transformer insulation and improves the dielectric properties of the medium. A very recent research contribution by Mehta et al. [2] conducted number of tests and concluded that natural ester is showing better insulating capabilitied over hydrocarbon oils.Vishavdeep Jindal and Jashandeep Singh [3], shows that fire resistive levels and moisture tolerance level of ester oil is better than mineral oil. Delgado et-al [4] reported that the mineral oil exhibits better heat transfer capabilities than vegetable oil based on the CFD simulations of fluid flow of mineral oil and vegetable ester using carried out by the authors. The effect of field enhancement factor near and around the particle of cylindrical shape existing in transformer is presented by a work conducted by Podenok et - al [5]. This paper deals with simulation of movement of spherical particle made up of different materials in synthetic esters having different viscosity using computational fluid dynamics.

\section{DESIGN OF TRANSFORMER}

A power transformer considered in this work is 100 MVA transformer which has HV side $220 \mathrm{kV}$ and LV side $11 \mathrm{KV}$. High voltage side is considered for analysis due to the impact of voltages when compared to low voltage side. In this winding, there are 58 discs winding combined as 29 disc pairs. Each winding is separated by a distance of $4 \mathrm{~mm}$ or $5 \mathrm{~mm}$ as per the design. Transformer oil is allowed to flow in between these windings. Oil moves inside transformer with the velocity of 0.5 metres per second to 1 metre per second according to the design of this transformer. Velocity of oil and particle are considered to be same i.e., 0.5 metre per second. Structure of the considered transformer is shown in figure1.

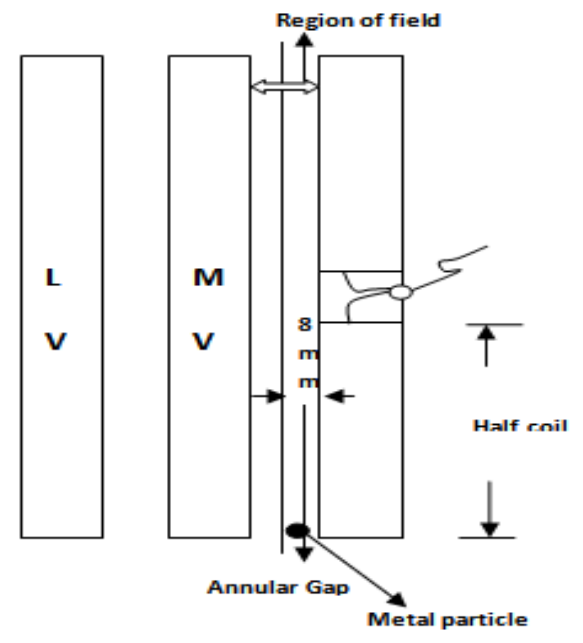

Figure 1 Structure of Power transformer winding 
Figure 2 shows the interleaved structure of the HV winding. The method called computational fluid dynamics is used to simulate the transformer arrangement and the fluid flow. This transformer has 58 discs numbered from top to bottom. Each winding has different voltages in top down manner.

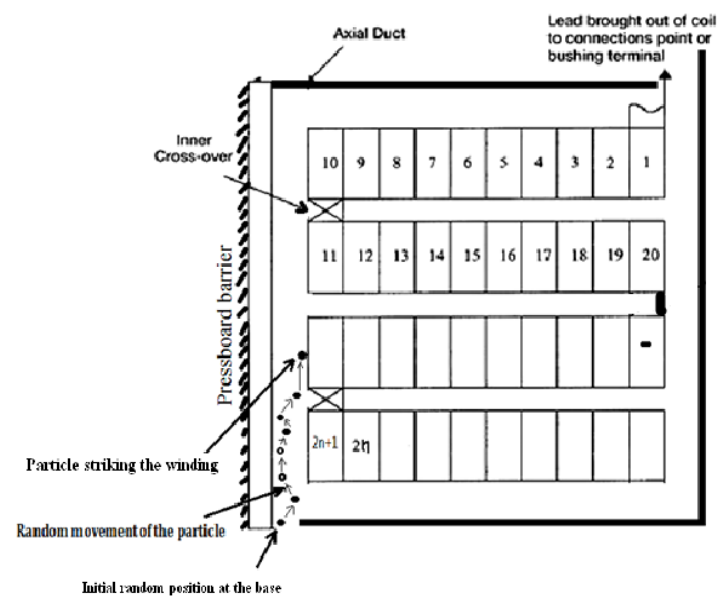

Figure 2 Interleaved winding structure

Fluid enters from bottom and flows through the winding and reaches the top and exit from there through nozzle. The oil is allowed to exit from winding space from top and allowed to re-enter from bottom to again cool winding space.

\section{SIMULATION OF FLUID FLOW AND PARTICLE MOVEMENT}

The software called ANSYS is used to simulate the transformer and flow of oil and particle. Copper and aluminium particles having spherical shape are considered to be available at the entry point of the oil. Particle starts its flight along with the oil at the fixed distances of $1 \mathrm{~mm}$, $4 \mathrm{~mm}$ and $7 \mathrm{~mm}$ from inner pressboard of the winding. Property of synthetic ester like viscosity and density are incorporated in the simulation.

Figure 3 shows the movement of copper spherical particle starting from $1 \mathrm{~mm}$ distance from pressboard. It can be seen that the particle is moving towards upward without any diversion and reaches disc 1 and settles on the top of the disc. The figure is tilted right to comfortably fit inside the given margin space. Particle movement is represented by a colour system based on particle resident time inside the transformer. Disc 1 is having a voltage of $127.16 \mathrm{kV}$. The stress formed on the particle is contributed by this voltage.
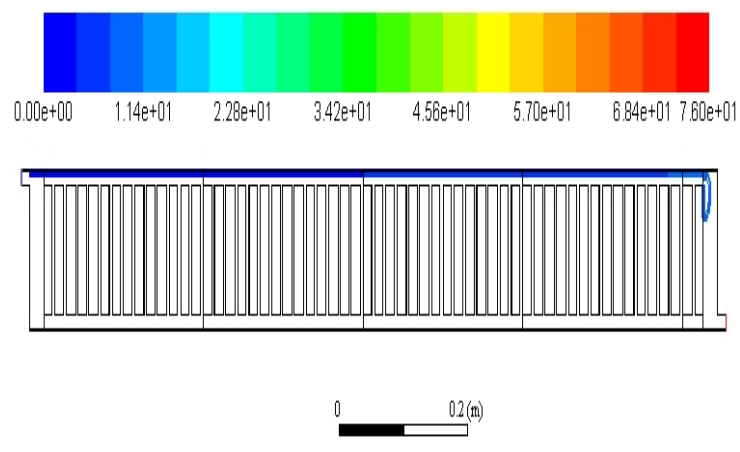

Figure 3 Trajectory of copper spherical particle for starting point of $1 \mathrm{~mm}$ 
Similar simulation is carried out for the gap values of $4 \mathrm{~mm}$ and $7 \mathrm{~mm}$ distance from the pressboard and shown in figure 4 and 5 respectively. The point of contact which is the destination of particle in the transformer is clearly seen in the figure.

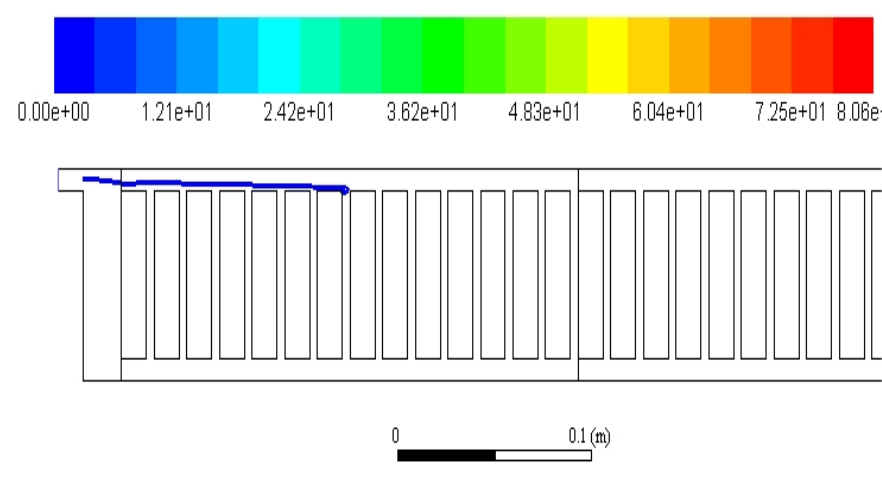

Figure 4 Trajectory of copper spherical particle for starting point of $4 \mathrm{~mm}$

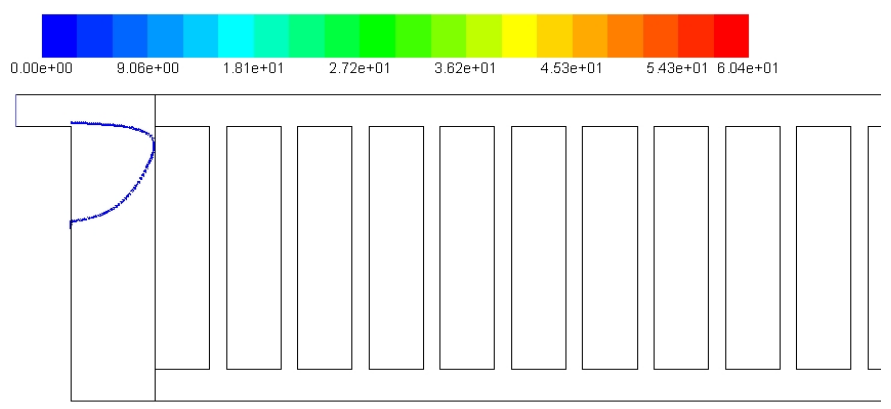

Figure 5 Trajectory of copper spherical particle for starting point of $7 \mathrm{~mm}$

The point of contact for the case of starting point is $4 \mathrm{~mm}$ and $7 \mathrm{~mm}$ is disc 52 and 58 respectively. Disc voltages are $82.34 \mathrm{kV}$ and $77.08 \mathrm{kV}$ respectively. Particle settling point is obtained as a factor of net oil force and gravitational force acting on the particle. Once the point of collision is found, stress on the particle is calculated. Stress formed on the particle is calculated as a resultant of voltage of disc of contact.

$$
\text { Stress }=\frac{\mathrm{V}_{1}-\mathrm{V}_{2}}{\mathrm{~d}} \quad---(1)
$$

Where

V1 - Voltage of electrode 1

V2 - Voltage of electrode 2

$\mathrm{d}$ - Distance between electrodes

Threshold value of considered synthetic ester is $75 \mathrm{kV} / \mathrm{cm}$. If the stress on the particle exceeds the breakdown strength of insulation then partial discharge is considered to happen. A consolidated report of disc of impact and stress values is shown in table 1 . The obtained stress is expressed in terms of percentage of breakdown stress. 
Table 1 Analysis of copper spherical particle

\begin{tabular}{|l|c|c|c|}
\hline \multicolumn{1}{|c|}{$\begin{array}{c}\text { Distance } \\
\text { from press board cylinder }\end{array}$} & $\begin{array}{c}\mathbf{1} \\
(\mathbf{m m})\end{array}$ & $\begin{array}{c}\mathbf{4} \\
(\mathbf{m m})\end{array}$ & $\begin{array}{c}\mathbf{7} \\
(\mathbf{m m})\end{array}$ \\
\hline $\begin{array}{l}\text { Disc of impact } \\
\text { (From top) }\end{array}$ & 1 & 52 & 58 \\
\hline $\begin{array}{l}\text { Location } \\
\text { after impact }\end{array}$ & $\begin{array}{c}\text { Settles at } \\
\text { disc }\end{array}$ & $\begin{array}{c}\text { Settles at } \\
\text { disc }\end{array}$ & $\begin{array}{c}\text { Settles at } \\
\text { bottom }\end{array}$ \\
\hline $\begin{array}{l}\text { Disc Voltage } \\
\text { at point of impact kV }\end{array}$ & 127.02 & 82.34 & 77.08 \\
\hline Stress without $(\mathrm{kV} / \mathrm{cm})$ & 4.96 & 0.22 & 0.56 \\
\hline \% of breakdown stress & $6.6 \%$ & $0.3 \%$ & $0.75 \%$ \\
\hline
\end{tabular}

Similar simulations have been carried out for aluminium spherical particle, considering the same stating positions at the bottom. Figure 6,7 and 8 shows the track of aluminium copper particles for the starting positions of $1 \mathrm{~mm}, 4 \mathrm{~mm}$ and $7 \mathrm{~mm}$ respectively.
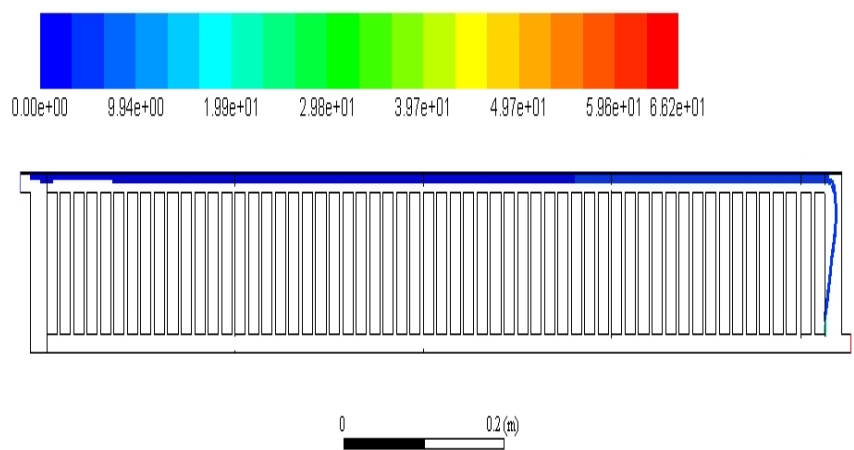

Figure 6 Trajectory of aluminium spherical particle for starting point of $1 \mathrm{~mm}$

When started from $1 \mathrm{~mm}$ aluminium particle moves along with the oil in upward direction and reaches the top disc. It settles on the other edge of the disc as a resulting force of oil in the particle side and oil moving from the other side of the winding.
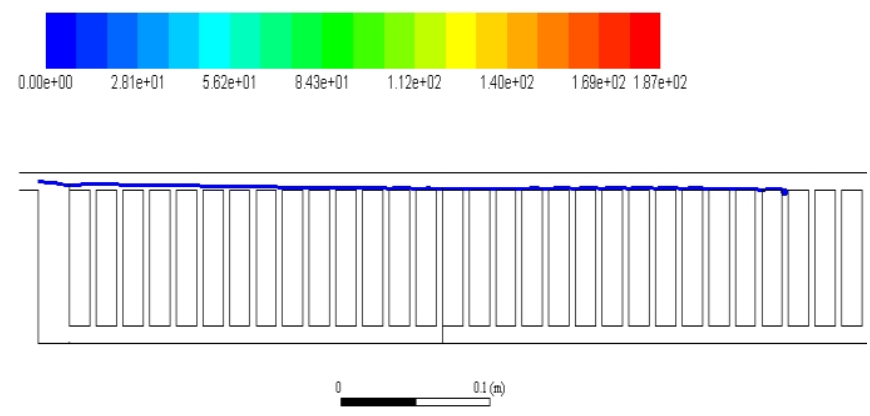

Figure 7 Trajectory of aluminium spherical particle for starting point of $4 \mathrm{~mm}$ 


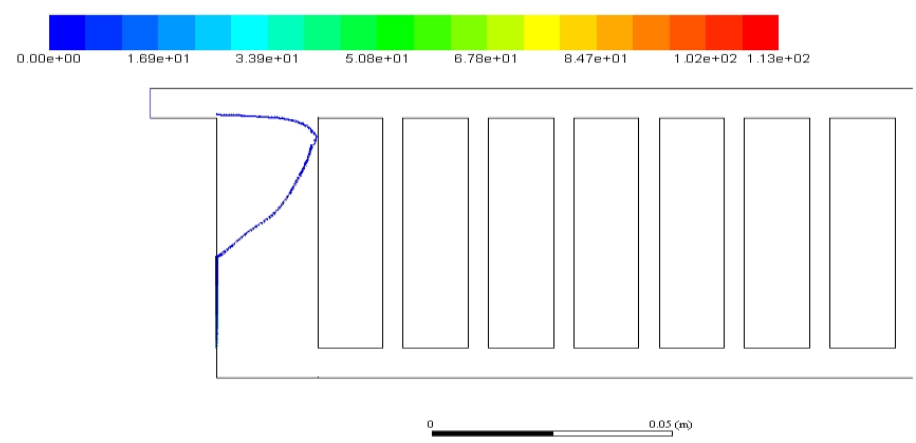

Figure 8 Trajectory of aluminium spherical particle for starting point of $4 \mathrm{~mm}$

The point of contact of aluminium spherical particle for starting point is $4 \mathrm{~mm}$ and $7 \mathrm{~mm}$ is disc 52 and 58 respectively. Disc voltages are as mentioned above. Stress on the particle is calculated as a resultant of voltage of disc of contact. Table 2 gives complete picture of trajectory of aluminium spherical particle.

Table 2 Analysis of copper spherical particle

\begin{tabular}{|l|c|c|c|}
\hline \multicolumn{1}{|c|}{$\begin{array}{c}\text { Distance } \\
\text { from press board cylinder }\end{array}$} & $\begin{array}{c}\mathbf{1} \\
(\mathbf{m m})\end{array}$ & $\begin{array}{c}\mathbf{4} \\
(\mathbf{m m})\end{array}$ & $\begin{array}{c}\mathbf{7} \\
(\mathbf{m m})\end{array}$ \\
\hline $\begin{array}{l}\text { Disc of impact } \\
\text { (From top) }\end{array}$ & 1 & 32 & 58 \\
\hline $\begin{array}{l}\text { Location } \\
\text { after impact }\end{array}$ & $\begin{array}{c}\text { Settles at } \\
\text { disc }\end{array}$ & $\begin{array}{c}\text { Settles at } \\
\text { disc }\end{array}$ & $\begin{array}{c}\text { Settles at } \\
\text { bottom }\end{array}$ \\
\hline $\begin{array}{l}\text { Disc Voltage } \\
\text { at point of impact } \mathrm{kV}\end{array}$ & 127.02 & 99.86 & 77.08 \\
\hline Stress without $(\mathrm{kV} / \mathrm{cm})$ & 4.96 & 1.97 & 0.56 \\
\hline$\%$ of breakdown stress & $6.6 \%$ & $2.6 \%$ & $0.75 \%$ \\
\hline
\end{tabular}

\section{DISCUSSIONS}

Synthetic ester is considered as an insulating medium instead of hydrocarbon oil. Breakdown voltage of synthetic ester is $75 \mathrm{kV} / \mathrm{cm}$. Copper and aluminium spherical particles projected at distances from pressboards move from bottom to top along with oil. When projected from 1 $\mathrm{mm}$ distance from pressboard both copper and aluminium particles reach disc 1 and settles there. When projected from $4 \mathrm{~mm}$ gap copper particle got stuck at disc 52 where as aluminium particle travelled up to disc 32 and settles on the disc. This is due to, at $1 \mathrm{~mm}$ distance particle is moving along side of the pressboard and oil force is much active in one side only. When projected from $4 \mathrm{~mm}$ oil force acts at both sides of the particle and hence got diverted at the middle of the flight. Another point noticed is that the distance travelled by copper and aluminium are different. This may be due to the fact that the copper is a high dense material when compared to aluminium. Hence oil could move aluminium to higher distance than copper. In all the cases particle resident time is less for aluminium when compared to copper particle. This is also the resultant of the reason that the lighter density of aluminium it moves faster than copper for the given oil force. 


\section{CONCLUSION}

Movement of copper and aluminium particles having diameter of $1 \mathrm{~mm}$ are simulated in CFD environment. Following points are observed form the simulations carried out

- Synthetic ester is having better breakdown strength compared to hydrocarbon oil.

- Aluminium particle reaches higher voltage discs when compared to copper particles hence contributing much for probability of partial discharge.

- Particle resident time is less in case of aluminium

- When particle started moving near inner wall they reach the high voltage discs.

- The highest stress obtained out of all cases is $4.96 \mathrm{kV} / \mathrm{cm}$, which is $6.6 \%$ of the breakdown voltage of synthetic ester.

- The lowest stress obtained is $0.22 \mathrm{kV} / \mathrm{cm}$ which is $0.3 \%$ of breakdown voltage of synthetic ester.

\section{REFERENCES}

[1] C.Perrier, A.Beroual and J.L Bessede, (2006) "Improvement of Power Transformers by using Mixtures of Mineral Oil with Synthetic Esters" IEEE Transactions on Dielectrics and Electrical Insulation Vol. 13, No. 3; June, PP 566-564

[2] Dhruvesh Mehta, P. Kundu, A. Chowdhury V.K. Lakhiani and A.S Jhala, (2016), "A Review on Critical Evaluation of Natural Ester vis-a-vis Mineral Oil Insulating Liquid for Use in Transformers: Part1, IEEE Transactions on Dielectrics and Electrical Insulation Vol. 23, No. 2; April, PP 873-880

[3] Vishavdeep Jindal, Jashandeep Singh, (2018) "A Chemically Customized Ester Fluid- A More Effective Liquid for Insulation" International Journal of Engineering and Advanced Technology (IJEAT) ISSN: 2249 - 8958, Volume-8 Issue-2.

[4] F.Delgado, I. Fernandez, F.Ortiz, C.Renedo, A.Ortiz, J. Carcedo (2015), "Thermal Analysis a/ Transformers Insulation Based on Vegetable Esters", IEEE Electrical Insulation Conference, 7-10 June, INSPEC Accession Number: 15412367, Print ISBN: 978-1-4799-7352-1.

[5] Sayed A. Ward, Adel A. ElFaraskoury and S. Sabry ElSayed, (2014), Experimental and Theoretical Study Of Breakdown Voltage Initiated By Particle Contamination in GIS, International Journal of Scientific Research Engineering \& Technology (IJSRET), ISSN 2278 - 0882 Volume 3, Issue 2.

[6] M.M.Mohsin, M.Rehrnan, R.S. Nema and M.N.Narayanachar, (2004) "Measurement of transformer oil dielectric strength", TENCON 2004- IEEE Region 10 Conference, 24 November, PP 436-439, Print ISBN: 0-7803-8560-8.

[7] T. Laneryd, R. Bel Fdhila, M. Rahmani, and A. Gustafsson, (2012), "Analysis Of Oil Flow Distribution In Power Transformer Winding Cooling Ducts Using Temperature Measurements", International Conference on Heat Transfer, Fluid Mechanics and Thermodynamics, 16 - 18 July, Malta. 